\title{
DESIDRATAÇÃO DA POLPA DE ACEROLA COM ADITIVOS (Malpighia emarginata) pelo processo foam-mat
}

\author{
G. P. MAFRA ${ }^{1}$, S. C. de M. DANTAS ${ }^{2}$, M. de F. D. de MEDEIROS ${ }^{3}$, I. P. MACHADO ${ }^{4}$ \\ ${ }^{1}$ Universidade Federal do Rio Grande do Norte, Departamento de Engenharia Química \\ ${ }^{2}$ Universidade Federal do Rio Grande do Norte, Departamento de Engenharia Química \\ ${ }^{3}$ Universidade Federal do Rio Grande do Norte, Departamento de Engenharia Química \\ ${ }^{4}$ Universidade Federal do Rio Grande do Norte, Departamento de Engenharia Química \\ E-mail para contato: gabrielamafra_@hotmail.com
}

\begin{abstract}
RESUMO - Estudou-se a influência dos aditivos albumina, pectina, Superliga ${ }^{\circledR}$, e Emustab ${ }^{\circledR}$, combinados em diferentes concentrações, no processo de secagem polpa de acerola em camada de espuma. Foram realizados 6 ensaios em ensaios em estufa a $60{ }^{\circ} \mathrm{C}$. As espumas foram caracterizadas quanto a umidade, densidade, expansão e estabilidade, sendo analisados. Foram determinadas a umidade e a atividade de água dos pós resultantes da secagem, bem como o tempo de reconstituição em água. O menor tempo de secagem (195 minutos) foi observado para a espuma de acerola com $2 \%$ de Superliga ${ }^{\circledR}, 4 \%$ de albumina e $2 \%$ de pectina, que apresentou a maior expansão e a menor densidade $(268,91 \% \mathrm{e}$ $\left.0,33 \mathrm{~g} / \mathrm{cm}^{3}\right) . \mathrm{O}$ pó obtido neste experimento apresentou atividade de água de 0,383 e $3,76 \%$ de umidade, com tempo de reconstituição de 100 segundos.
\end{abstract}

\section{INTRODUÇÃO}

A aceroleira (Malpighia emarginata) é uma planta de clima tropical cujos frutos apresentam alto teor de vitamina $\mathrm{C}$, valores estimados entre 1200 a $1900 \mathrm{mg} 100^{-1} \mathrm{~g}$ de polpa (Paiva et al., 2003), além de ser rica em antocianinas e de baixo valor calórico.

Devido ao fato de apresentar uma maturação rápida, o fruto perde sua firmeza (textura) e tem sua coloração, sabor e aroma modificados (Alves, 1996). Nesse contexto, a desidratação surge como método capaz de prolongar a vida útil e impedir a deterioração e perda do valor comercial. Na secagem em camada de espuma, alimentos líquidos e semilíquidos são transformados em uma espuma estável através da adição de agentes químicos com propriedades emulsificantes, espessantes e estabilizantes (Soares et al 2001). É um processo considerado de baixo custo, bastante utilizado no processamento de produtos termicamente sensíveis. Segundo Dantas (2010), o processo oferece como vantagens o menor tempo de desidratação, devido à maior área de contato exposta ao ar, bem como remoção mais rápida de água e a obtenção de um produto facilmente reidratável.

A utilização de aditivos no processo de secagem não visa interferir nos aspectos nutricionais do alimento, mas modificar suas características físico-químicas, biológicas ou sensoriais do preparo à ingestão, de modo que suas concentrações não devem ultrapassar às estipuladas pela legislação, a qual estipula suas identificações nos rótulos. 
Os espumantes, como a albumina, têm a função de gerar gases e provocar a expansão do material, reduzindo sua densidade e possibilitando a formação ou manutenção de uma dispersão uniforme. Já os estabilizantes, além de estabilizar emulsões, são capazes de aumentar a viscosidade do produto final, a exemplo da Superliga ${ }^{\circledR}$ (estabilizante e espessante). O Emustab® é um emulsificante capaz de auxiliar na estabilidade e na secagem, visto que permite a movimentação da umidade pelo processo de capilaridade graças à separação da camada líquida pela espuma, enquanto que a pectina apresenta funções estabilizantes e espessantes.

No Brasil, a Agência Nacional de Vigilância Sanitária (ANVISA) não estabelece limites para a utilização da pectina em tecnologia de alimentos, visto que ela ocorre naturalmente em frutas, especialmente as cítricas. A albumina e a Superliga ${ }^{\circledR}$ também não possuem restrições. Por outro lado, o limite para emulsificantes compostos por monoestearato de polioxietileno (20) sorbitana e polisorbato 60 varia conforme o tipo de alimento, entre $0,1 \mathrm{~g}$ a $1 \mathrm{~g}$ de emulsificante para cada $100 \mathrm{~g}$ de alimento, cujas especificações devem estar em conformidade com a ANVISA. Considerando todavia, a importância de se obter produtos em pó de modo que na sua composição não seja extrapolada a concentração de aditivos, estudouse neste trabalho a combinação ótima de aditivos que promovam a formação da espuma da polpa de acerola, minimizando o tempo de desidratação e a obtenção do produto em pó, microbiologicamente estável, com baixo teor de umidade e facilmente reidratável.

\section{MATERIAIS E MÉTODOS}

Foram utilizadas polpas de acerola adquiridas em mercado local em embalagens plásticas de $100 \mathrm{~g}$, trazidas para o Laboratório de Tecnologia de Alimentos da UFRN em caixas térmicas e mantidas congeladas até a utilização. Determinaram-se a densidade e umidade das polpas de acerola, cujos valores médios foram 1,21 g/ $\mathrm{cm}^{3}$ e 91,57\%, respectivamente. As formulações testadas estão reunidas na Tabela 1.

Tabela 1 - Formulações testadas

\begin{tabular}{ccccc}
\hline Formulação & Emustab & Superliga & Albumina & Pectina \\
F1 & $0 \%$ & $0 \%$ & $4 \%$ & $0 \%$ \\
F2 & $1 \%$ & $1 \%$ & $4 \%$ & $0 \%$ \\
F3 & $1 \%$ & $1 \%$ & $4 \%$ & $2 \%$ \\
F4 & $0 \%$ & $0 \%$ & $4 \%$ & $4 \%$ \\
F5 & $0 \%$ & $2 \%$ & $4 \%$ & $2 \%$ \\
F6 & $2 \%$ & $0 \%$ & $4 \%$ & $2 \%$ \\
\hline
\end{tabular}

De acordo com Barreto (2011), para a pitanga roxa, uma concentração excessiva de albumina não reduziu mais a densidade da espuma, pois um aumento da concentração de albumina de $4 \%$ para $8 \%$ diminuiu a densidade em apenas $24 \%$. Por outro lado o aumento da concentração de $0 \%$ a $4 \%$ diminuiu a densidade da espuma em $75 \%$. Com base nestes dados para a albumina, manteve-se a concentração de $4 \%$ em massa fixa em todos os ensaios. 
$\mathrm{Na}$ preparação das espumas, a polpa foi previamente descongelada e pesada, adicionando-se os aditivos conforme a formulação a ser preparada (Tabela 1), sendo a mistura submetida à agitação constante por 15 minutos em batedeira doméstica em velocidade média. Ao final do batimento, cada espuma foi submetida à determinação de sua umidade - em estufa até peso constante - densidade (picnometria), expansão e estabilidade. Esta última análise consistiu em avaliar o volume de líquido drenado, conforme um sistema composto por proveta de $10 \mathrm{~mL}$, funil de haste longa de $50 \mathrm{ml}$ e filtro de gaze, em conformidade com as técnicas descritas por Karim e Wai (1999). Para o cálculo da densidade, expansão e estabilidade foram empregadas as equações 1 a 3.

$\rho_{\text {espuma }}=\frac{m_{\text {espuma }}}{V_{\text {picnômetro }}}$

Expansão $=\frac{\frac{1}{\rho_{\text {espuma }}}-\frac{1}{\rho_{\text {polpa }}}}{\frac{1}{\rho_{\text {polpa }}}} \times 100$

Estabilidade $=\frac{1}{V_{\text {drenado }}}$

Em todos os experimentos, a espuma foi distribuída em uma placa antiaderente com $0,5 \mathrm{~cm}$ de espessura, $24,5 \mathrm{~cm}$ de diâmetro e a secagem realizada em estufa com circulação de ar com temperatura controlada de $60{ }^{\circ} \mathrm{C}$, acompanhando-se a perda de massa através de pesagens realizadas em intervalos de 15 minutos até a verificação da massa constante. Ao final da secagem, realizou-se a raspagem da placa, obtendo-se o produto em pó, o qual foi analisado determinando-se a atividade de água (analisador tipo AQUALAB), umidade (balança de umidade com infravermelho) e seu tempo de reconstituição em água. Para este teste, calculou-se, através de um balanço material, a massa de água destilada a ser adicionada a $5 \mathrm{~g}$ de pó para ser reconstituído com o auxílio de um agitador magnético.

\section{RESULTADOS E DISCUSSÃO}

Os testes preliminares consistiram na determinação da estabilidade e densidade de cada espuma cujos resultados constam na Tabela 2. Com relação ao teste de estabilidade, a espuma F1 com 4\% de albumina, foi a única que coalesceu no intervalo de tempo de 1 minuto, observando-se assim a importância da combinação dos aditivos na formação de uma espuma estável. Utilizando como critério que o valor recomendado como ideal para a densidade da espuma deve estar compreendido entre 0,1 e $0,6 \mathrm{~g} / \mathrm{cm}^{3}$, conforme Soares et al (2001), verifica-se na Tabela 2 que as espumas F1 com 4\% de albumina e F4 com 4\% de albumina e $4 \%$ de pectina estão fora desta faixa, pois apresentam densidades de 0,81 e 0,76 $\mathrm{g} / \mathrm{cm}^{3}$, respectivamente. Para a polpa de acerola, a adição apenas de albumina ou albumina combinada com pectina não foi suficiente para formar uma espuma com expansão adequada. Com base neste resultado não foram realizadas as secagens destas espumas. 
As demais espumas apresentaram densidades compreendidas entre 0,33 e $0,42 \mathrm{~g} / \mathrm{cm}^{3} \mathrm{e}$ expansões superiores a 190\%, destacando-se a espuma com a formulação F5 cuja expansão de 269\% promoveu importante diminuição no tempo de secagem (190 minutos) como se pode verificar nas curvas ilustradas na Figura 1. Em conformidade com Thuwapanichayanan et al (2008), a menor densidade da espuma significa uma difusão de água mais rápida e mais fácil na secagem.

Tabela 2 - Resultados

\begin{tabular}{|c|c|c|c|c|c|c|c|}
\hline Espumas & $\begin{array}{c}\text { Umidade } \\
(\%)\end{array}$ & $\begin{array}{c}\text { Densidade } \\
\left(\mathrm{g} / \mathrm{cm}^{3}\right)\end{array}$ & $\begin{array}{c}\text { Expansão } \\
(\%)\end{array}$ & $\begin{array}{c}\text { Estabilidade } \\
\left(1 / \mathbf{c m}^{3}\right)\end{array}$ & $\begin{array}{l}\text { Atividade } \\
\text { de água }\end{array}$ & $\begin{array}{c}\text { Umidade } \\
\text { do pó } \\
(\%)\end{array}$ & $\begin{array}{c}\text { Tempo de } \\
\text { reconstituição } \\
\text { (s) }\end{array}$ \\
\hline F1 & 87,73 & 0,81 & 50,29 & 0,58 & - & - & - \\
\hline F2 & 87,95 & 0,42 & 189,86 & $\begin{array}{l}\text { Totalmente } \\
\text { estável } \\
\text { Totalmente }\end{array}$ & 0,272 & 3,83 & 20 \\
\hline F3 & 85,75 & 0,37 & 229,03 & $\begin{array}{l}\text { estável } \\
\text { Totalmente }\end{array}$ & 0,517 & 6,20 & 80 \\
\hline F4 & 84,17 & 0,76 & 60,18 & $\begin{array}{c}\text { estável } \\
\text { Totalmente }\end{array}$ & - & - & - \\
\hline F5 & 85,74 & 0,33 & 268,91 & $\begin{array}{l}\text { estável } \\
\text { Totalmente }\end{array}$ & 0,383 & 3,76 & 100 \\
\hline F6 & 86,60 & 0,42 & 189,86 & estável & 0,412 & 5,30 & 40 \\
\hline
\end{tabular}

Na Figura 1 também se verifica que a curva de secagem desta espuma apresenta um decaimento mais acentuado da umidade, o que se traduz em maiores taxas de evaporação da água. Com relação ao efeito dos aditivos sobre o comportamento da secagem das espumas, verifica-se que a adição de $2 \%$ de pectina a espuma F3 não provocou modificações importantes na secagem visto que as curvas relativas as espumas F2 e F3 encontram-se praticamente sobrepostas a partir dos 30 minutos, atingindo a condição de equilíbrio aos 250 minutos. Por outro lado, o tempo de secagem da espuma F6 preparada sem adição da Superliga ${ }^{\circledR}$ foi o mais longo, 300 minutos, enquanto o da espuma F5 sem Emustab ${ }^{\circledR}$ e com adição de $2 \%$ de Superliga ${ }^{\circledR}$ foi de 190 minutos. Verifica-se, desta forma, o importante efeito da Superliga ${ }^{\circledR}$ na combinação dos aditivos utilizados na formulação das espumas.

Fernandes et al (2014) observaram que a adição de albumina reduziu o tempo para atingir a umidade de equilíbrio na secagem de polpa de tomate em 190 minutos. Concluíram, ainda, que formulações com albumina reduzem a influência dos açúcares e ácidos orgânicos presentes no tomate, altamente hidrofílicos, os quais contribuem para o aumento da umidade do pó. No presente trabalho, como a concentração de albumina foi mantida fixa na preparação de todas as espumas, o efeito da concentração deste aditivo combinados com a concentração dos demais aditivos não pode ser avaliado. 
Figura 1 - Curvas de secagem das espumas de acerola.

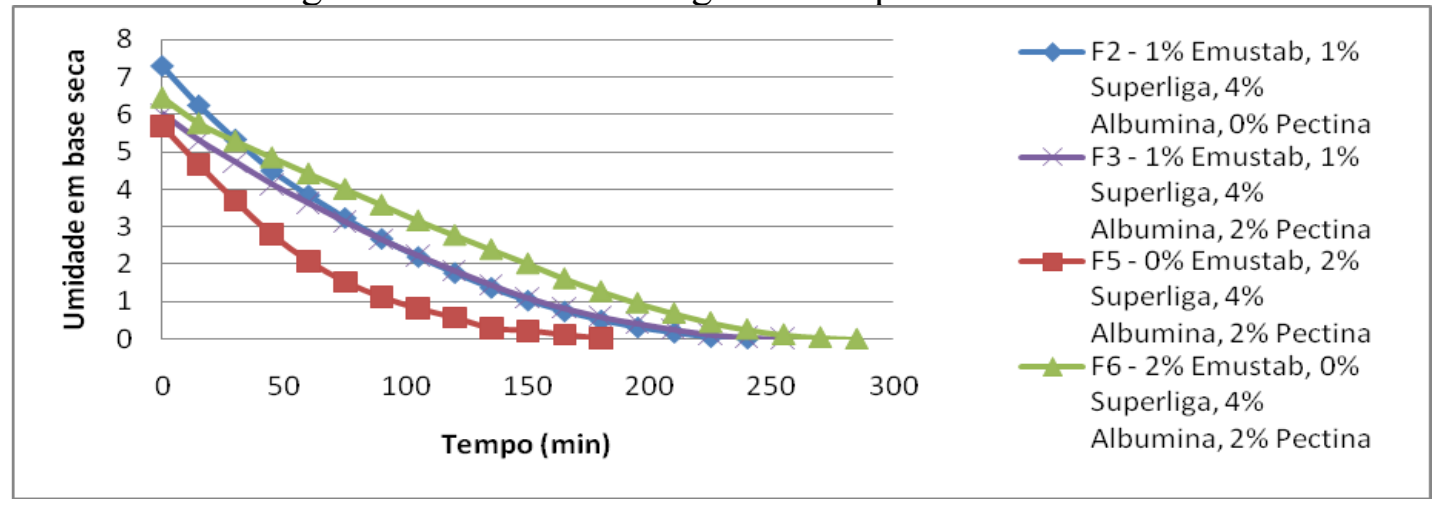

Na Figura 2 pode-se observar os pós produzidos nos ensaios de secagem e as polpas reconstituídas por reidratação dos pós. Visualmente constata-se a qualidade das polpas reconstituídas com preservação da cor e textura da polpa original. O pó resultante da secagem da espuma F5 foi o que apresentou maior tempo de reconstituição enquanto o da espuma F2 preparada sem adição de pectina apresentou reconstituição quase instantânea. Estes resultados indicam a importante influência dos aditivos e da combinação entre eles sobre a solubilidade dos pós. A atividades de água inferiores a 0,6 caracterizam todos os pós como alimentos estáveis, embora a umidade dos pós provenientes da secagem das espumas F3 e F6 estejam acima de 5\%, valor considerado relativamente elevado para alimentos em pó.

Em comparação com pós de acerola liofilizados, Nogueira (1991) obteve 8\% de umidade e Leme et al (1973), obtiveram 4\% de umidade, ao passo que Borges (2011) desidratou o bagaço da acerola em leito de jorro cujo pó apresentou 7,20\% em umidade.

Figura 2 - Pós reconstituídos.

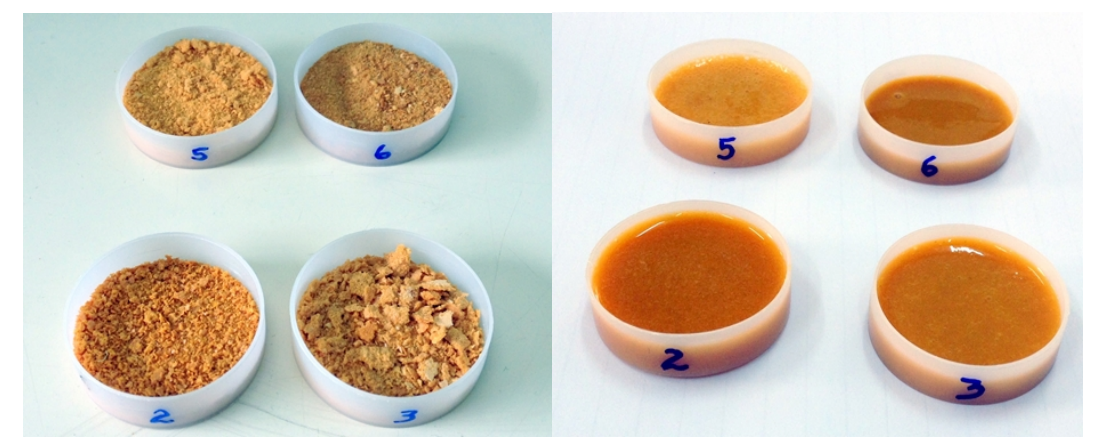

\section{CONCLUSÕES}

Os resultados do presente trabalho, embora preliminares, demonstram a importância da combinação dos aditivos na secagem de polpas de frutas em camada de espuma, tanto no que diz respeito a formação da espuma com expansão e estabilidade adequada, como a diminuição no tempo de secagem e as características do produto final obtido. 


\section{REFERÊNCIAS}

ALVES, R. E. Características das frutas para exportação. In: GORGATTI NETTO, A. et al. Acerola para exportação: procedimento de colheita e pós-colheita. Embrapa-SPI, Brasília, 1996.

BARRETO, I. M. A. Caracterização de polpa de pitanga roxa (Eugenia uniflora) desidratada em leito de espuma. Itapetininga: Universidade Estadual do Sudoeste da Bahia, 2011.

BORGES, K. C. Estudo das características físico-químicas e funcionalidade de bagaços de frutas tropicais desidratadas em leito de jorro. Dissertação de Mestrado, UFRN, Natal, 2011.

DANTAS, S. C. de M. Desidratação de polpas de frutas pelo método foam-mat. Dissertação de Mestrado, UFRN, Natal, 2010.

FERNANDES, R. V. de B.; QUEIROZ, F.; BOTREL, D. A.; ROCHA, V. V.; SOUZA, V. R. de.; LIMA, C. F. de. Estudo da adição de albumina e da temperatura de secagem nas características da polpa de tomate em pó. Semina: Ciências agrárias, Londrina, v. 35, n. 3, p. 1267-1278, maio/junho, 2014.

KARIM, A. A.; WAI, C. C. Foam-mat drying starfruit (Averrhoa carambola L.) purée. Stability and air drying characteristics. Food Chemistry. n. 64, p. 337 - 343, 1999.

LEME, Jr. J. et al Variação do teor de ácido ascórbico e beta-caroteno em cereja das Antilhas (Malpighia punicifolia L.) liofilizada. Archivos Latinoamericanos de Nutrition. v.23, n. 2, p. 207-213, 1973.

SOARES, E. C.; OLIVEIRA, G. S. F. de.; MAIA, G. A.; MONTEIRO, J. C. S.; SILVA Jr., A.; S. FILHO, M. de S.. Desidratação da polpa de acerola (Malpighia emarginata D.C.) pelo processo foam-mat. Campinas, 2001.

NOGUEIRA, C.M.C. da C.D. Estudo químico e tecnológico da acerola (Malpighia glabra L.). Fortaleza, 1991, 117p. (Dissertação de Mestrado), Universidade Federal do Ceará (UFC).

PAIVA, J. R. de, ALVES, R. E., BARROS, L. de M., CRISÓSTOMO, J. R., MOURA, C. F. H., ALMEIDA, A. S., NORYES, N. P. Clones de aceroleira. Embrapa Agroindústria Tropical, Fortaleza, 2003.

THUWAPANICHAYANAN, R.; PRACHAYAWARAKORN, S.; SOPONRONNARIT, S. Drying characteristics and quality of banana foam-mat. Journal of Food Engineering, Amsterdam, v. 86, n. 4, p. 573-583, 2008. 